\title{
Simulation of Switching Arc Using Modified Mayr Arc Model
}

$\begin{array}{lll}\text { Member } & \text { Yerzan Eshaf } & \text { (Tbko Electric Corp.) } \\ \text { Member } & \text { Masanori Matsuoka } & \text { (Tbko Electric Comp) } \\ \text { Non-member } & \text { Mitsuhino Kuramochi } & \text { (Toko Eleatric Corp.) } \\ \text { Non-member } & \text { Yoshimasa Taniguchi } & \text { (Tbko Electric Corp.) } \\ \text { Member } & \text { SatoakiArai } & \text { (Tbkyo Denki univensity) }\end{array}$

Abstract This paper presents an experimental investigation on interaction between anc voltages and anc length And a black box anc model based on modified Mayr arc equation is developed to describe the influence of arc length on arc voltages. In this model the coefficient of anc power loss is defined to be depending on the anc length. The numerical analysis is performed on EMTP. The behavior of arc is represented using Thevenin type-94 component of MODELS.

Keywords switching arc, modified Mayr equation, saw-tooth wave, models type 94 component, EMTP

\section{Introduction}

Switching devices are complex elements in electrical power systems. The switching surges in the electrical power systems, that caused by closing or opening operations of switching devioes, are generally defined by mutual effects between the arc behavior of switching devices and the corresponding circuit conditions. The aim of a black box anc model is to describe the interaction between the arc and the corresponding circuit. Although a large number of black box arc models based on Mayr's or Cassie's equations have been developed ${ }^{[1+2 x}$, but contrasting with the models of other elements such as cables or electrical machines, the arc models did not content the increasing demands for the numerical analysis of transient phenomena in electrical power systems, due to the conplexity of the physical phenomena of anc.

This paper presents experimental investigation on the arc voltage characteristics of $\mathrm{SF}_{6}$ gas switches (GS), air switches (AS) and vacuum switches (VS). To describe the influence of arc length on arc voltage, a black box arc model based on modified Mayr arc model is developed. In this model, the onefficient of the anc power bos is modified to be depending on the are length The numerical analysis is performed on electromagnetic transients program (EMTP). The behavior of arc is represented using type-94 component of MODELS.

\section{Characteristics of the arc voltages}

The interaction between the arc voltages and arc length in interrupting bad currents, using GS, AS and VS is investigated experimentally. The experimental cincuit is shown in Fig. 1. Where GS is a specially designed switch for observing the arc form simultaneously with the anc voltages and the arc currents using a high-speed video camera.

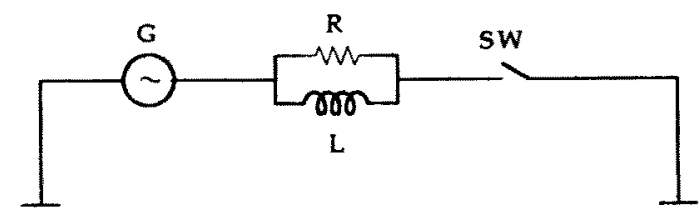

G: generator

R and Liload

SW: GS, AS and VS

Fig. 1 Experimental circuit

It has been recognized that the arc voltages increase with increase in arc length, and the arc becomes longer due to

(a) Increase in gap length in separating operation

(b) Magnetic force of supply current

(c) Convection of the surrounding gas

\subsection{Gap length}

Fig.2 shows the measured arc voltage and arc current in intermpting bad current using GS, AS and VS. In Fig.2 (a), the ar voltage has a tendency to increase with increase in gap length (function of time). The arc voltage Varc can be divided into two parts of Voa and Vos as shown in dot lines, where Voa is the total fall voltage of anode and cathode, $V_{0}$ is the increase in the arc voltage. For AS as shown in Fig.2 (b), the arc voltage indeases with 


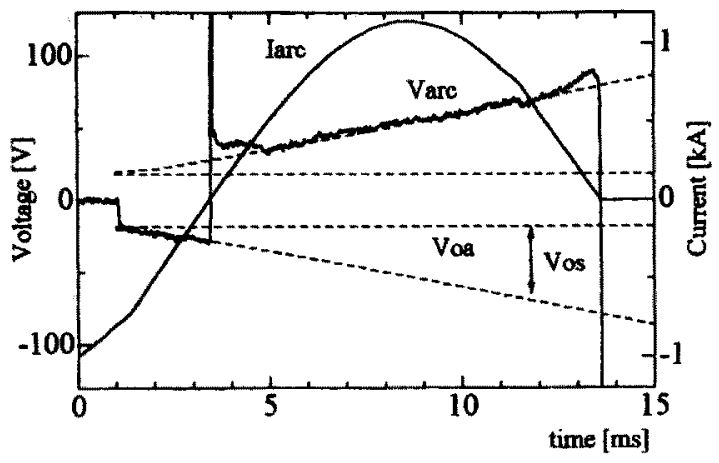

(a) GS

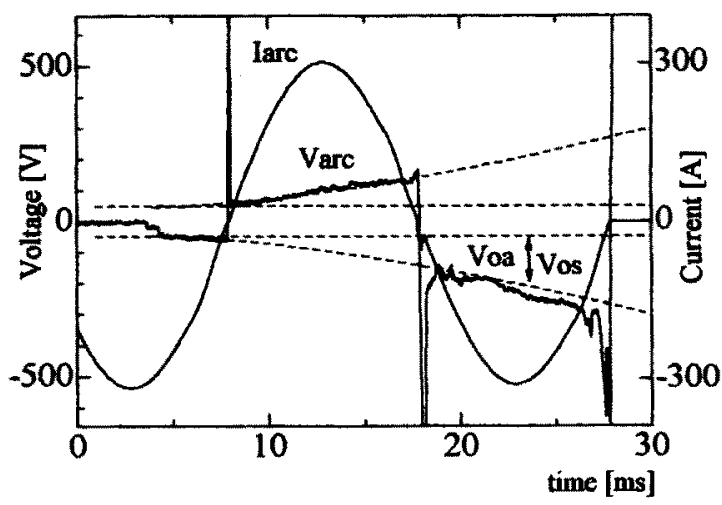

(b) AS

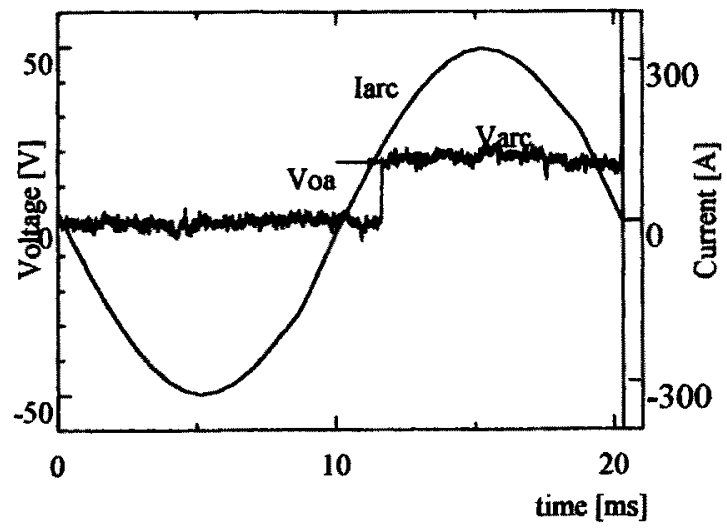

(c) VS

Fig.2 Arc voltage charactenistics of GS, AS and VS

increase in gap length as for GS. But there is difference in amplitude of $\mathrm{Voa}$ and $\mathrm{Vos}$, because of the difference in behave of extinction modium as well as separating speed of AS and GS. The arc voltages Varc of GS and AS can be expressed by Eq.1. Vos can be experimentally expressed by an exponential function of gap length by Eq.2, where $S$ is gap length coeficient $k_{s}$ and exponent $\rho$ are constants.

Contrasting with GS and AS, the anc voltage of VS is independent

$$
\begin{aligned}
& \mathrm{V}_{\mathrm{a} \times \mathrm{c}}=\mathrm{V}_{\mathrm{oa}}+\mathrm{V}_{\mathrm{os}} \\
& \mathrm{V}_{\mathrm{os}}=\mathrm{k}_{s} \mathrm{~s}^{\rho}
\end{aligned}
$$

of the gap length, and keeps a constant value of Voa in the whole arcing time, as shown in Fig.2(c). Eq. 1 can also be used to represent the arc voltage of VS by omitting Vos.

\section{$<2.2>$ Saw-troth wave}

Fig.3 shows the arc voltage of GS with saw-tooth wave Vot. In this case, the arc voltage increases with increase in gap length as in Fig.2 (a), and saw-tooth waves Vot, caused by sharply increases and straightly drops of arc valtages, appeared for several times. The occurrenoe process of the saw-tooth waves can be explained by the corresponding arc forms that shown in Fig.4, which taken using a high-speed camera simultaneously with the anc voltages and the currents. The axis of contacts is showed by arnows in Fig.4, where the upper is the moving contact and the lower is the state contact. To distinguish the arc path from background, the photographs are processed. Photographs (a)-(d) is the anc profiles around 16, 17, 23 and 24 millisec in Fig.3, respectively. The arc paths are nearty in a straight line between two contacts in photograph (a) and (b), and the saw-tooth waves didn't oocur during the corresponding time in Fig.3. The arcs are elongated in multiple loops in photographs (c) and (d), and the effective anc length reached up to nearty 5 times as long as in photographs (a) and (b), and the saw-tooth waves appeared during the corresponding time in Fig.3. For the duration before 14millisec in Fig.3 that without saw-tooth waves, the anc forms ane similar to those as shown in Fig.4 (a) and Fig.4 (b).

The occurrence of shamply increase of arc voltages is considered due to the magnetic force or the convection of the surrounding gas. And the resin for straightly drop of the anc voltages are considered due to the short cincuit of the arc that elongated in multiple-bops. Acoonding to the experimental results there are statistic characteristics in the occurrence time and the amplitudes of sawtooth waves. The experiment was carried out for 10 times for each current of $200 \mathrm{~A}, 600 \mathrm{~A}$ and $800 \mathrm{~A}$, respectively. The measured ancing times ane within one and half cycle and the saw-tooth wave only cocurs in the last half cycle. The incidenoe of saw-tooth wave increases with increase in arc current, as given in Table.1.

Table. 1 Incidenoe of the saw-tooth

\begin{tabular}{|c|c|c|c|}
\hline Current (A) & 200 & 600 & 800 \\
\hline Incidence (\%) & 0 & 20 & 70 \\
\hline
\end{tabular}

The arc voltage with saw-tooth waves can be represented by Eq. 3, where Vot is a function of time.

$$
\mathrm{Var} c=V_{0} a+\mathrm{V}_{\mathrm{s}}+\mathrm{V}_{\mathrm{ot}}
$$




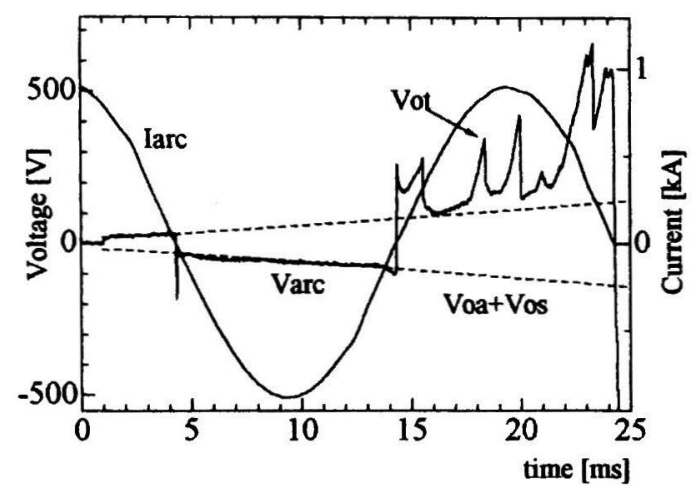

Fig.3 The arc voltage with saw-tooth waves (GS)

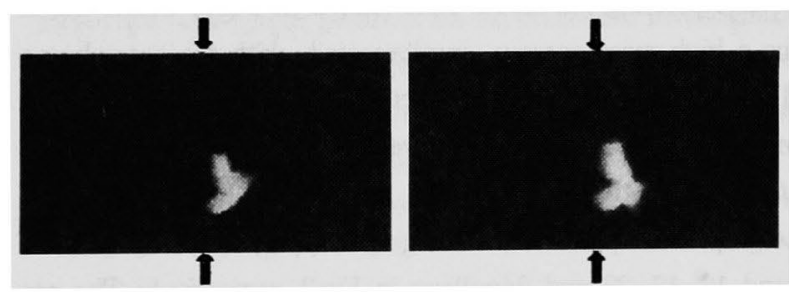

(a) $t=16 \mathrm{~ms}$

(b) $t=17 \mathrm{~ms}$

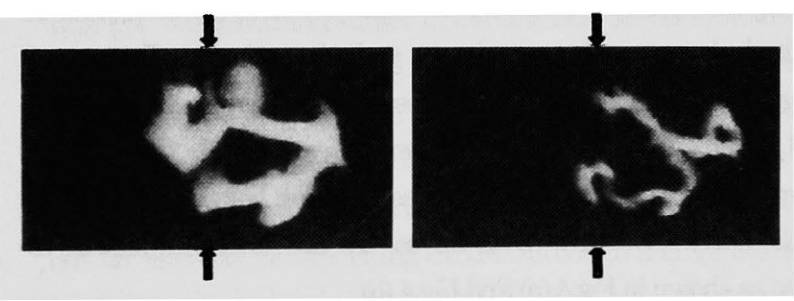

(c) $\mathrm{t}=23 \mathrm{~ms}$

(d) $\mathrm{t}=24 \mathrm{~ms}$

Fig.4 Arc form corresponding to Fig.3

\section{Numerical analysis}

3.1 Arc model

Mayr first described the basic behavior of arc by a black box arc model expressed by Eq. 4,

$$
\frac{1}{G} \frac{d G}{d t}=\frac{1}{\theta}\left(\frac{\mathrm{vi}}{P}-1\right)
$$

where $G$ is arc conductance, $v$ and $i$ are arc voltage and anc current, respectively. Since the time constant $\theta$ and power loss $P$ are constant, this model was only used to describe the arc behavior qualitatively, but it cannot be used for quantitative analysis. Along with the progress in techniques of the experimental measurement and the numerical simulation, a great number of modified arc models with variable parameters or combinations of several models were proposed.
T.E.Browne ${ }^{[1]}$ and Grega Bizjak ${ }^{[2]}$ described the arc by a combined Cassie-Mayr equation. Where using Cassie model before current zero, and Mayr model after current zero, and constant ax parameters $\theta$ and $P$ were used.

E.V.Bonin ${ }^{[37}$ proposed an arc model which expressed by Eq.5, on the assumption that the arc time constant $\theta$ and the arc power loss $\mathrm{P}$ of the original Mayr model Eq.4 depended on the arc conductance G. Eq.5 is generally called as modified Mayr arc model This model is very sensitive in current zero period and useful for simulation of high-frequency extinction of $\mathrm{GCB}^{\left[{ }^{4}\right.}$.

$$
\frac{1}{G} \frac{d G}{d t}=\frac{1}{\theta_{0} G^{\alpha}}\left(\frac{v i}{P_{0} G^{\beta}}-1\right)
$$

These models described above are insufficient for calculating the arc voltage characteristics described above in their original formula, because the arc voltage at the peak value of arc current will be the same value of Voa. This can be proved by Fig. 5 where the anc voltages at the peak values of arc current, calculated by using Eq. 5 with a constant value of $\mathrm{Po}$, are equal to Voa, shown by dot line. Recently, M.Kizikay ${ }^{(0)}$ presented an arc model based on the equation of Hochrainer to calculate the fault arc in air. Where the stationary arc voltage was assumed to be not constant for fault ancs burning in air freely, but it depends on the arc length and partly on the short-cincuit current flowing through the arc. The influenoe of the arc length on the anc voltages for secondary arcs was expressed by defining the stationary anc voltage or the arc time constant as a function of arc length

In this paper, the modified Mayr anc model Eq.5 is used to describe the dynamic behavior of switching arc. To represent the rise of arc voltage with increase in anc length described above, we assumed that the arc power loss $\mathrm{P}$ to be depending on the arc length According to Eq. 3, the coefficient Po is divided into three parts as expressed in Eq. 6 ,

$$
\mathrm{P}_{0}=\mathrm{P}_{\mathrm{o} a}+\mathrm{P}_{\mathrm{os}}+\mathrm{P}_{\mathrm{ot}}
$$

where, Poa, Pos and Pot are assumed to be corresponding to Voa, Vos and Vot in Eq. 3, respectively. Poa is a constant, and Eq. 6 becomes the coefficient of Eq. 5 when Pos and Pot are omitted. To express the effects of the gap length on the arc voltages represented by Eq.2, Pos is determined as a function of gap length as,

$$
\mathrm{P}_{\mathrm{os}}=\mathrm{K}_{\mathrm{PS}}{ }^{\sigma}
$$

where $\mathrm{k}_{\mathrm{p}}$ and $\sigma$ are constant, $\mathbf{S}$ is gap length. The third component Pot, which applied to represent the saw-tooth waves Vot, is represented by Eq. 8 ,

$$
P_{o t}=\lambda\left(e^{\left(t-t_{n}\right)^{\gamma}}-1\right) \sum_{n=1}^{n}\left(u\left(t-t_{n}\right)-u\left(t-t_{n}-\Delta T\right)\right)
$$

where $u(t)$ is a unit step function, $t_{w} \Delta T$ and $n$ are the occurrence 
time, the width and the occurrence numbers of saw-tooth waves, respectively. $\lambda$ and $\gamma$ are constants. As an example, Fig. 5 (b) shows the calculated arc voltages and currents by using Eq. 5 , where $\mathrm{Po}$ is described by Eq. 6 (Pot=0). Compared with the cakculation result of using a constant value for $\mathrm{Po}$ shown in Fig. 5(a), Fig. 5(b) is corresponding to the measured characteristics of anc voltage shown in Fig. 2 well.

The arc parameters of Eq.5 can be derived from the measured waveforms of anc voltages and anc currents, but in this paper, it is difficult to derive the anc parameters precisely, due to the influence of Vos and Vot. In this paper, the same values of $\alpha=0.5, \beta=1.0$ are applied to three type switches For $\theta_{0}$, the maximum values for which the sucoessful arc extinction occurred is applied. For the other parameters, the value that suitable for the measured waveforms are applied. The initial condition of arc conductance is $0.2 \mathrm{~S}$, and the limit value of anc conductance for extinction is $10^{10} \mathrm{~S}$. Although it has been pointed out that Eg. 5 was only applicable to air and $\mathrm{SF}_{6}$ gas arcs, it was unsuited to vacuum arcs because the

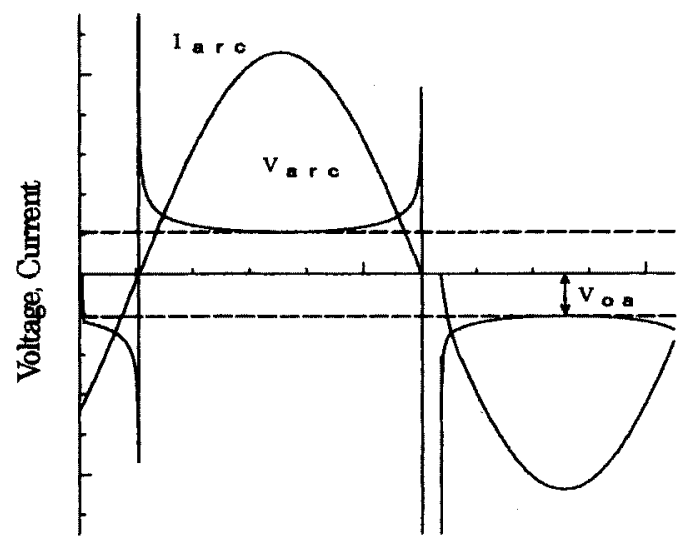

(a) $\mathrm{Po}=$ Constant

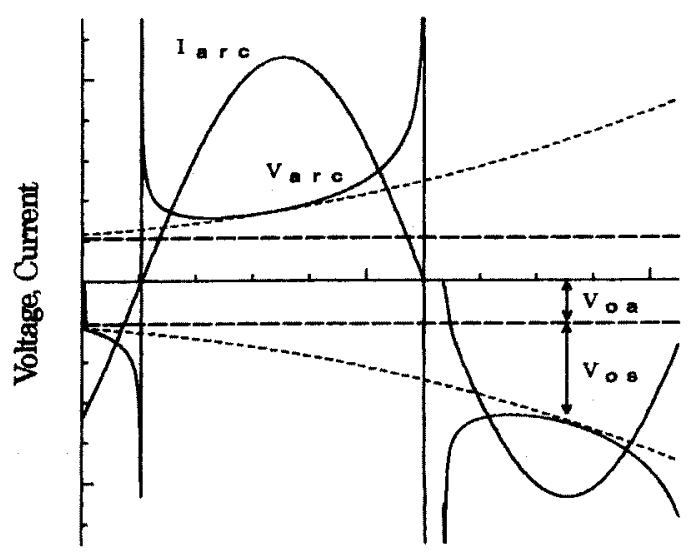

(b) $\mathrm{Po}=\mathrm{Poa}+\mathrm{Pos}$

Fig. 5 Calculated arc voltage and current thermal process is less significant in vacumm switch devioes. We have proved that as a mathematical model, Eq. 5 was applicable to calculate the arc voltages and arc currents of vacuum switch ${ }^{\circ}$.

The numerical cakculation is performed on EMTP, and the anc equation is calculated using nonlinear component TYPE94 of MODELS

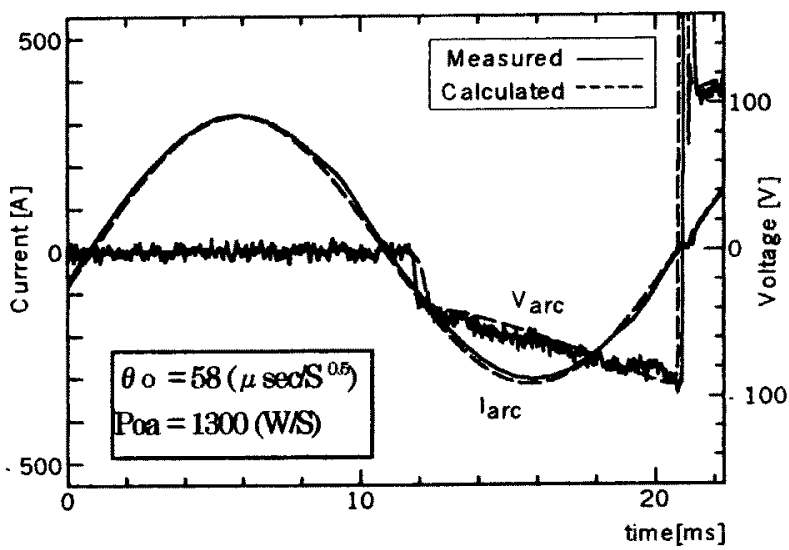

(a) AS

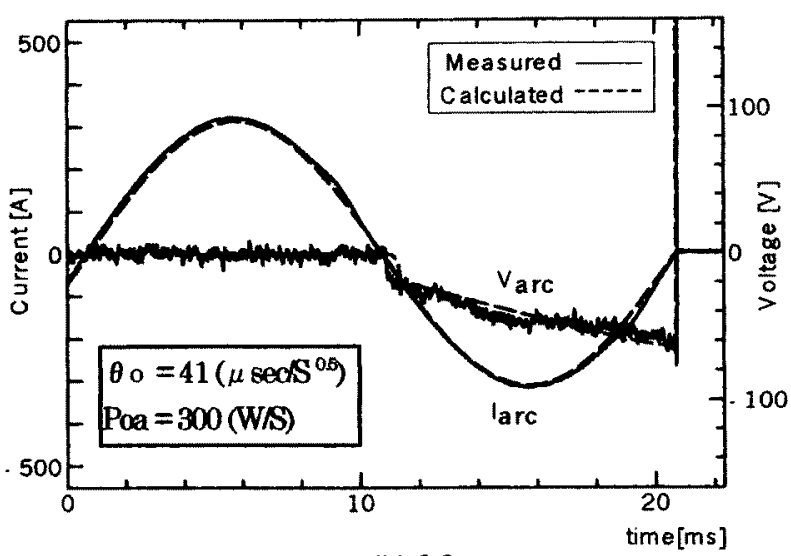

(b) GS

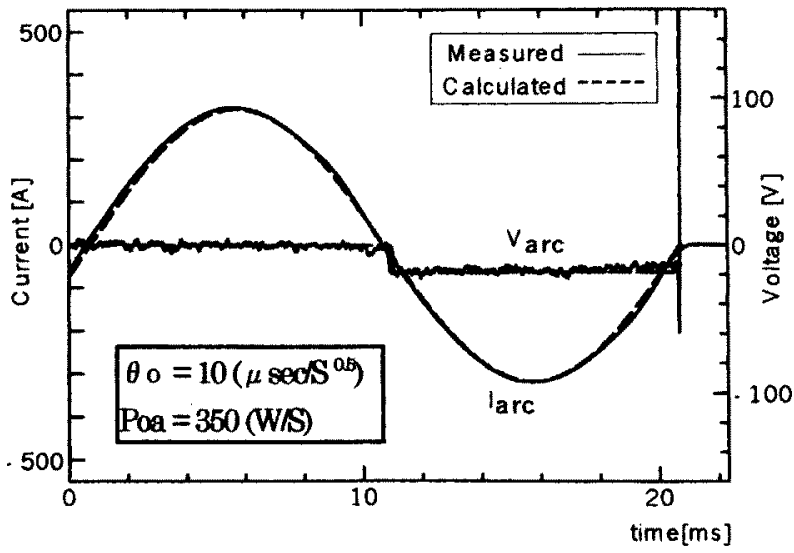

(c) VS

Fig.6 Extinction behavior of AS, GS and VS 


\subsection{Cakculated results}

3.2.1 Extinction behavior Fig. 6 shows the difference in the extinction behavior of AS, GS and VS. For all cases, the arc current is $200 \mathrm{~A}$ and the arcing time is half cycle. The sucossful anc extinction cocurred in the case of using GS and VS, but reignition occurred in the case of using AS. The variation of the anc time constant $\theta$ and the anc power loss $P$ against to the anc cuments are shown in Fig.7. Both $\theta$ and $P$ decrease in the onder of AS, GS and VS. The calculated vahues of $\theta$ for air was larger than that for $\mathrm{SF}_{6}{ }^{[7}$, but the value of $\theta$ and $\mathrm{P}$ for $\mathrm{AS}$ and $\mathrm{GS}$ is very similar in this paper. Although the conditions such as extinguishing chamber and extinguishing method for AS, GS and VS are different in this paper, but the main reason for that is that the AS used in this paper has an arc extinction pipe, and arc extinction effect is mainly based on the cracked gas from the arc extinction pipe.

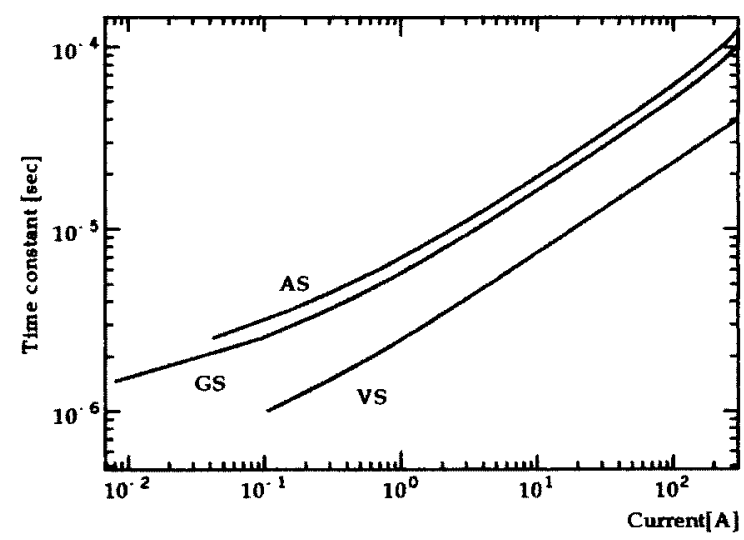

(a) Arc time constant vs arc current

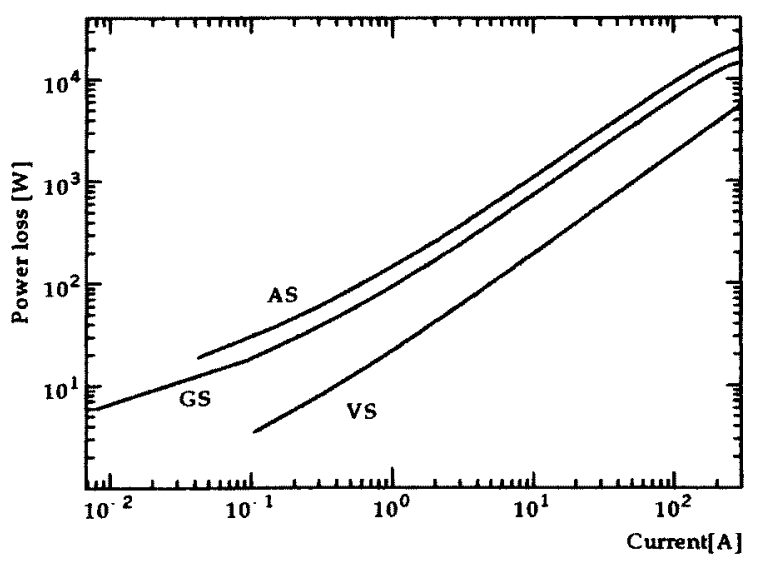

(b) Arc power loss vs arc current

Fig. 7 Arc time constant and power loss

\subsubsection{Influence of gap length}

Fig.8 shows the measured and calculated results of arc voltage of AS. In this case, reignition occumed for two times in current zero, where, the measured dielectric voltages in the current zero were used in calculation. Good agreement between the calculated and the measured results of the arc voltage was achieved. Same result is obtained for GS.

\subsubsection{Saw-tooth waves}

Fig.9 shows the measured and cakculated results of anc voltage of GS with the saw-tooth wave. The quantitative calculation for al cases is difficult, because of the statistic characteristics in the occurrence time and the amplitude of the saw-tooth wave.

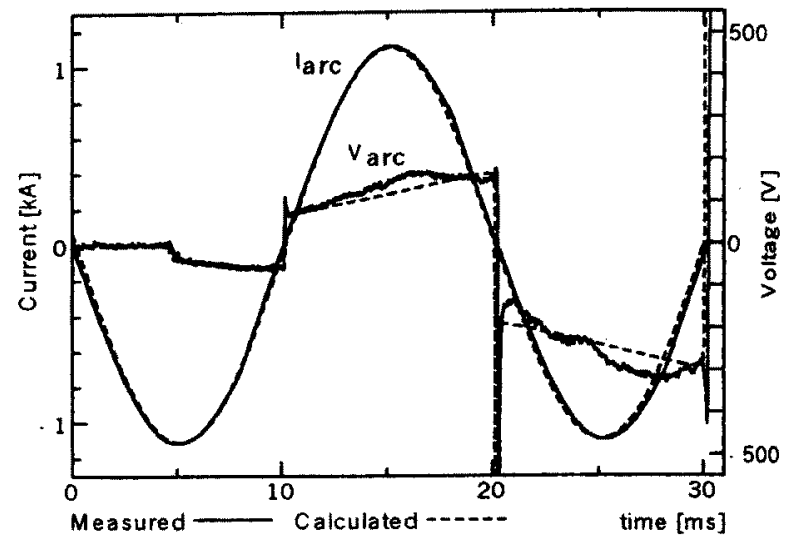

$\theta \mathrm{o}=35\left(\mu \mathrm{sec} \mathrm{S}^{05}\right), \mathrm{Poa}=1300$ (W/S $)$

Fig. 8 Influence of gap length on anc voltages (AS)

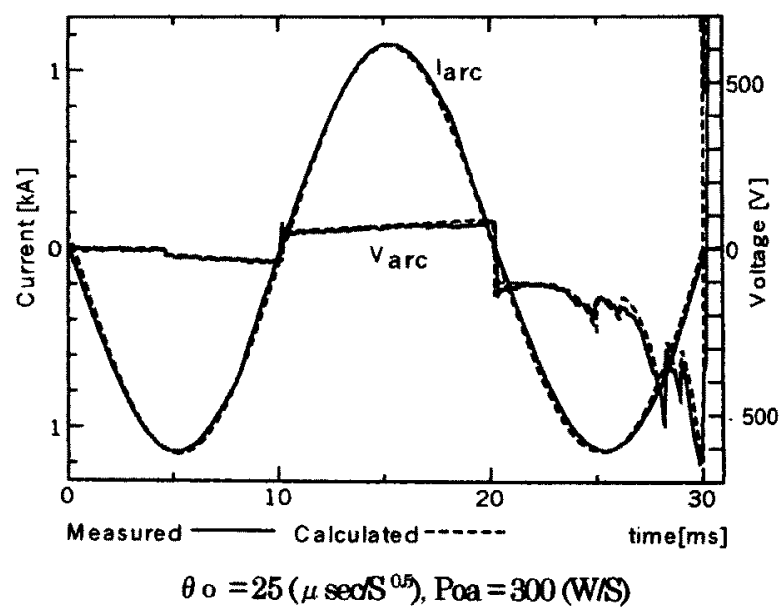

Fig. 9 Saw-tooth wave

\section{Conchusions}

This paper presented an experimental investigation on the characteristics of arc voltages, and a black box arc model based on modified Mayr arc model was developed to describe the influenoe of the arc length on the arc voltages. In this model, it was assumed that the coefficient of anc power loss Po to be consisted of three components of Poa, Pos and Pot, according to the characteristics of 
measured arc voltage. Although the derivation of the parameters relevant to the model and the representation of the statistic characteristics of saw-tooth wave are difficult. But the simulation method is considered to be applicable to various types of switches such as GS, AS and VS, by choosing suitable parameters for each type of switch It is the subject to investigate the statistic characteristics of saw-tooth wave.

(Manuscript received December 28, 2000, revised July $16,2001)$

\section{References}

[1] T. E. Browne, "Practical modeling of the circuit breaker arc as a short line fault interrupter", IEEE Transaction on Power Apparatus and system, Vol PAS-97, No.3, May/Jume 1978.

[2] Grega Bizjak, Peter Zunko, Dusan Powh, "Cincuit breaker model for digital simulation based on Mary's and Cassia's differential arc equation", IEEE Transaction on Power Delivery, Vol. 10, No.3, July 1995.

[3] E. V. Bonin, et al "Advanced Methods of Cincuit-Breaker Enginering", Conf on High Voltage Switching Equipment, Sydney (May 29-30, 1979)

[4] E.zaima, S.Okabe, S.Nishiwaki, M.Ishikawa, K.Suzuki, H.Tbda, "Application of dynamic arc equations to high-frequency arc extinction in $\mathrm{SF}_{6}$ gas cincuit breakers", IEEE Transaction on Power Delivery, Vol 8, No.3, July 1993

[5] M.Kirilcay, "Evaluation of existing secondary arc models", EEUG News May 1997.

[6] Y. Eshaf, S. Hamada, S.Arai, "Calculation of high-frequency current intermution in vacuum switch", T.IEE Japan, Vol 117B, No.12, 1997.

[7] Y.Yokomizu, K.Ito, T.Kojima, T.Matsumura, "Time constants and conductance of wall-stabilized arcs burning in different gases", IWHV'2000, ED-00=121, SP-00-29, HV-00-39, November, 2000.

Yerzan Eshaf (Member) was born on Oct. 3, 1964. He received the

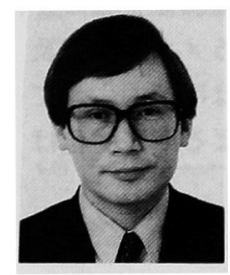
MS. and $\mathrm{PhD}$. degrees in electrical engineering from 'Tokyo Denki University in 1996 and 1999, respectively. He joined Tbko Electric Corporation in 1999. His research interests include the simulation of the arc and the transient phenomena in electrical circuits.
Masanori Matsuoka (member) received the $\mathrm{PhD}$. degree in

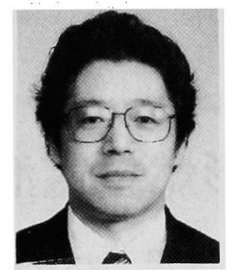
electrical engineering from Tokyo Denki University in 1999. Presently, he is a General Manager of Engineering R\&D Development Laboratory of Toko Electric Corporation. He has worked on development of devices and systems for the distribution systems.

Mitsuhiro Kurimoto (non-member) was born on Apr. 3, 1967. He

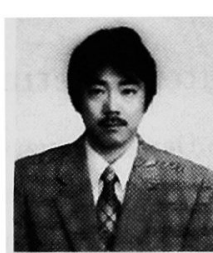
graduated from the electric course of Nippon Engineering College in 1990 . He joined Thko Electric Corporation in 1999. His research interests include the high voltage testing technology, arc discharge and the analysis of the switching surges.

Yoshimasa Taniguchi (non-member) was born on Apr. 11, 1968.

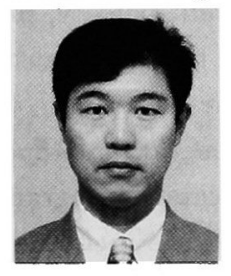

He received the B. S. degree in mechanical engineering from Chiba Industrial University in 1992. He joined Toko Electric Corporation in 1992. His research interests include the design and development of switchgear.

Satoaki Arai(member) received the $\mathrm{PhD}$. degree in electrical

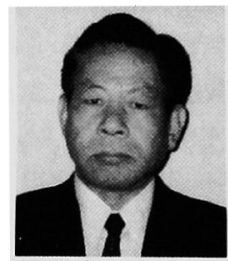
engineering from Tokyo Denki University in 1968. Presently, He is a professor at Tbkyo Denki University. He is currently interested in the current limiting fuses, electromagnetic transient and arc phenomena. 